\title{
KARAKTERISTIK DAN PERSEPSI PETANI TERHADAP INOVASI TEKNIK SOIL BIOENGINEERING UNTUK MITIGASI LONGSOR DI KABUPATEN BANJARNEGARA JAWA TENGAH
}

(Characteristics and farmers'perception to Soil Bioengineering technique for mitigation of landslide at Banjarnegara Regency, Central Java)

\author{
Baharinawati W. Hastanti ${ }^{1}$ dan Pranatasari Dyah Susanti ${ }^{1}$ \\ ${ }^{1}$ Balai Penelitian dan Pengembangan Teknologi Pengelolaan DAS \\ JI A Yani. Pabelan, Kartasura. PO.BOX 295 Surakarta/57102.Telp (0271)716709, 716959 \\ Email: baharina_06@yahoo.co.id
}

Diterima: 16 April 2019; Direvisi : 1 Juli 2019; Disetujui : 28 Agustus 2019

\begin{abstract}
Soil Bioengineering technique is a soil and water conservation technology innovation for landslide mitigation. The success of technological innovation is influenced by the perception and characteristic of the user community. This study aimed to determine the characteristics of farmers as potential users and their perceptions that were measured based on an assessment of characteristics of technology innovation. This study used a qualitative approach combined with the support of qualitative data quantification. Data collected consist of primary data and secondary data. Primary data include the characteristics of respondents and their perceptions of Soil Bioengineering innovation in the form of assessment variables consisting of certain indicators which are then measured using a Likert scale. The characteristics of farmers prospective users of Soil Bioengineering techniques are: 1) productive age, 2) lack of education (junior high school), 3) narrow land ownership (0.1 to 0.3 hectares), 4) the commodity planted is salak, 5) experience as farming (16 - 20 years) and, 6) medium/ middle income levels (3- 4.9 million rupiah per month). Farmer's perceptions are generally positive to Soil Bioengineering. Positive perception techniques if it was measured based on: 1) relative advantage, 2) compatibility, 3) simplicity, 4) trialability and 5) observability.
\end{abstract}

Keywords: perception; community; innovation; technique; soil bioengineering; mitigation; landslide

\begin{abstract}
ABSTRAK
Teknik Soil Bioengineering merupakan inovasi teknologi konservasi tanah dan air untuk mitigasi longsor. Keberhasilan inovasi teknologi ini dipengaruhi oleh persepsi dan karakteristik masyarakat pengguna. Penelitian ini bertujuan untuk mengetahui karakteristik petani sebagai calon pengguna dan persepsinya yang diukur berdasarkan penilaian terhadap karakteristik inovasi teknik Soil bioengineering. Penelitian ini menggunakan pendekatan kualitatif yang dipadukan dukungan kuantifikasi data kualitatif. Data yang dikumpulkan berupa data primer dan data sekunder. Data primer meliputi karakteristik responden dan persepsinya terhadap inovasi Soil Bioengineering yang berupa variabel-variabel penilaian yang terdiri dari indikator-indikator tertentu yang
\end{abstract}


kemudian diukur dengan menggunakan skala Likert. Karakteristik petani calon pengguna teknik Soil Bioengineering adalah: 1) berusia produktif, 2) berpendidikan rendah (SMP), 3) luas kepemilikan lahan yang sempit (0,1 sampai 0,29 hektar), 4) komoditi yang ditanam adalah salak, 5) Berpengalaman sebagai bertani (16 - 20 tahun) dan, 6) tingkat pendapatan yang sedang/ menengah (3- 4,9 juta rupiah per bulan). Persepsi petani umumnya positif terhadap teknik Soil Bioengineering. Mempunyai persepsi positif bila diukur berdasarkan: 1) keuntungan relatif, 2) kesesuaian, 3) kesederhanaan, 4) ketercobaan/ dapat dicoba dan 5) keteramatan/ dapat diamati.

\section{Kata kunci: persepsi; masyarakat; inovasi; teknik; soil bioengineering; mitigasi; longsor}

\section{PENDAHULUAN}

Bencana tanah longsor merupakan jenis bencana geologi yang sering terjadi di Indonesia. Tanah longsor atau gerakan massa tanah adalah proses perpindahan atau pergerakan massa tanah dengan arah miring atau vertikal dari kedudukan semula sebagai akibat gaya berat. Tanah longsor atau sering disebut longsor terjadi saat intensitas curah hujan tinggi, kondisi lereng yang miring hingga terjal, pelapukan tebal, batuan dan struktur geologi bervariasi dan penggunaan lahan yang kurang sesuai dengan karakteristik lahannya (Setiawan, 2014). Menurut Badan Nasional Penanggulangan Bencana (BNPB) telah terjadi 1.681 bencana yang menyebabkan korban jiwa sebanyak 259 orang, yang sebagian besar merupakan korban bencana longsor. Hal ini disebabkan banyaknya wilayah Indonesia yang termasuk daerah rentan terhadap longsor. Terdapat 918 lokasi rentan longsor yang tersebar di berbagai wilayah, diantaranya Jawa Tengah 327 lokasi, Jawa Barat 276 lokasi, Sumatera Barat 100 lokasi, Sumatera Utara 53 lokasi, Yogyakarta 30 lokasi, Kalimantan Barat 23 lokasi, sisanya tersebar di Nusa Tenggara Timur (NTT), Riau, Kalimantan Timur, Bali, dan Jawa Timur (BNPB, 2012 dalam Susanti, Miardini, \& Harjadi, 2017). Bencana alam longsor merupakan salah satu bencana alam yang banyak menimbulkan korban jiwa dan juga kerugian material, seperti rusaknya lahan pertanian, permukiman, jalan, jembatan, saluran irigasi dan prasarana fisik lainnya. Dampak longsor terhadap produktivitas tapak lebih berat, tetapi luasannya jauh lebih kecil jika dibandingkan dengan dampak erosi permukaan (Sari, 2016).

Selanjutnya Setiawan (2014) juga mengatakan untuk mengurangi kerugian yang timbul akibat bencana longsor, pemerintah dengan stakeholder yang lain perlu melaksanakan program mitigasi bencana longsor. Masyarakat yang tinggal di daerah rawan bencana longsor umumnya mengetahui daerahnya merupakan daerah yang rawan longsor, namun mereka tidak mempunyai pilihan lain untuk tinggal. Oleh karena itu, mereka mempunyai strategi dalam menghadapi bencana tersebut seperti menanam bambu sebagai penguat lereng, membunyikan kentongan sebagai peringatan terjadinya bencana dan berbagai aturan dan larangan, sebagai bentuk kearifan lokal. Pengetahuan penduduk lokal tentang mitigasi bencana tanah longsor terbentuk dari pola pikir penduduk yang tinggal di daerah dengan kondisi lingkungan yang rawan terhadap longsor sebagai suatu bentuk adaptasi.

Komponen penting dari upaya mitigasi dan adaptasi bencana longsor adalah penguatan kapasitas masyarakat dalam bentuk 
peningkatan pengetahuan dan pemahaman terhadap kawasan rawan bencana tanah longsor. Hal tersebut mampu menggerakkan dan mendorong masyarakat untuk meningkatkan upaya perbaikan kondisi lingkungan dalam bentuk pembentukan KMTB (Kelompok Masyarakat Tanggap Bencana) dan aplikasi sistem agroforestri sebagai bentuk adaptasi, mitigasi bencana tanah longsor serta peningkatan produktivitas lahan yang berkelanjutan (Nugroho, Soedjoko, Kusumandari, \& Marhaento, 2013).

Teknik konservasi tanah dan air sangat diperlukan pada daerah yang berpotensi longsor sebagai upaya mitigasi untuk mencegah longsor, degradasi lahan serta untuk mempertahankan produktivitas tanah (Idjudin, 2011). Salah satu teknik konservasi tanah dan air yang dapat diterapkan adalah metode Soil Bioengineering. Metode ini memanfaatkan tanaman hidup, maupun bagian tanaman yang telah mati yang disusun dalam sebuah konstruksi dengan tujuan mencegah gerakan tanah (Tejakusuma, 2016). Penerapan teknik konservasi tanah dan air ini dapat dimanfaatkan dan diaplikasikan oleh masyarakat yang tinggal pada wilayah yang rentan terhadap bencana tanah longsor. Seperti disampaikan oleh Zakaria, Muslim, Sophian, Kuswaryan, \& Tanuwirya (2013) bahwa teknik bioengineering memiliki keuntungan karena dapat digunakan untuk rekayasa lereng pada wilayah yang rawan terhadap longsor.
Fakta di lapangan menunjukkan bahwa adopsi inovasi teknologi pertanian di tingkat petani masih relatif rendah, karena beragam persepsi dan respons petani terhadap inovasi teknologi tersebut. Persepsi masyarakat terhadap teknik konservasi tanah dan air tersebut juga perlu diketahui. Dalam tataran konsep inovasi, teknologi yang diciptakan perlu mempertimbangkan kebutuhan pengguna dan faktor-faktor pendukungnya sehingga inovasi teknologi dapat diadopsi secara cepat dan tepat (Aditiawati, Rosmiati, $\&$ Sumardi, 2014). Tujuan penelitian ini adalah mengetahui karakteristik petani yang diharapkan menjadi pengguna inovasi teknik Soil Bioengineering serta mengetahui persepsinya terhadap teknik konservasi tersebut, sebagai pengukuran awal terhadap adopsi teknologi untuk mitigasi tanah longsor.

\section{BAHAN DAN METODE}

\section{A. Waktu dan Lokasi}

Penelitian dilakukan di Desa Sijeruk Kecamatan Banjarmangu Kabupaten Banjarnegara, Provinsi Jawa Tengah pada bulan April sampai dengan November 2018. Daerah ini mengalami longsor tepatnya di Bukit Pawinihan Desa Sijeruk pada 4 Januari 2006 yang telah menelan korban 77 orang tewas, 8 orang hilang, 14 orang luka berat, serta ratusan warga lain mengungsi (Irayani, Permanajati, Haryadi, Wihantoro, \& Azis, 2016). Peta lokasi penelitian disajikan dalam Gambar 1. 


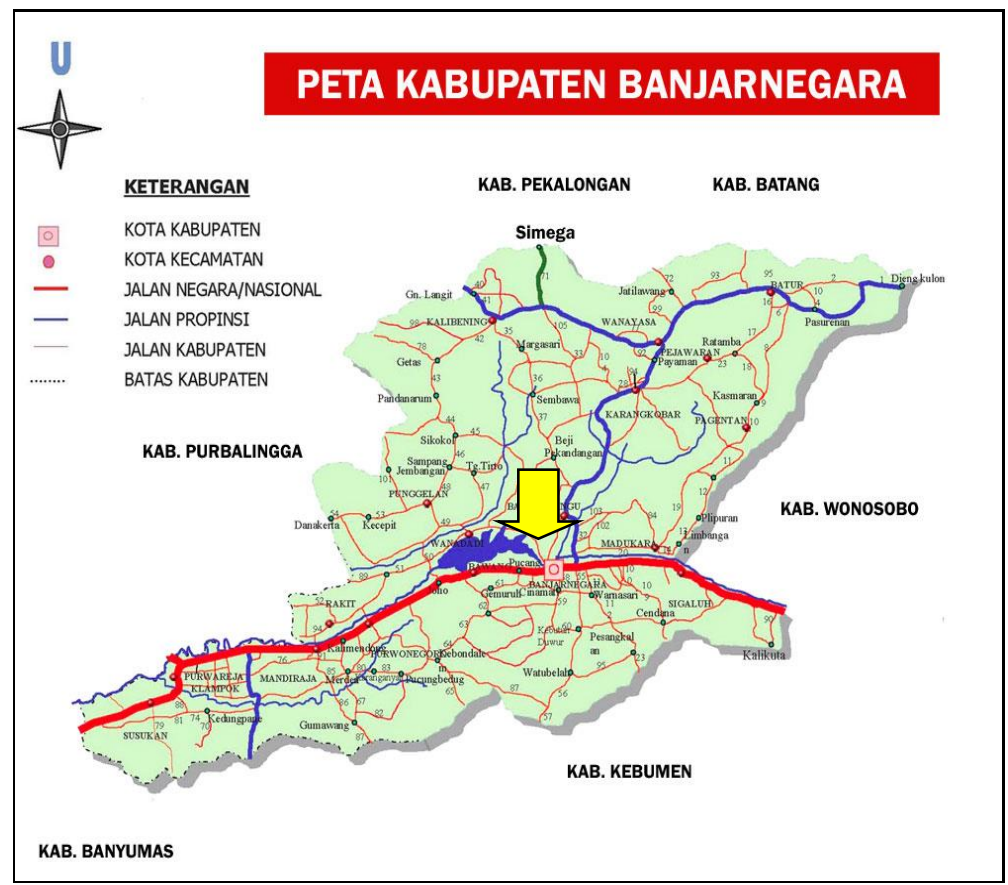

Gambar (Figure) 1. Peta Lokasi Penelitian/ Map of research location

Sumber (Source) : Pemerintah Kabupaten Banjarnegara (Local regency of Banjarnegara), (2018)

\section{B. Bahan dan Alat}

Alat dan bahan yang digunakan dalam penelitian ini adalah: alat tulis menulis, kuisioner, kamera dan komputer.

\section{Metode Penelitian}

\section{Teknik Pengumpulan Data}

Data yang dikumpulkan terdiri dari data primer dan data sekunder. Data primer dikumpulkan melalui pengamatan dan wawancara terstruktur dengan menggunakan kuisioner terhadap responden. Responden terdiri dari 35 petani yang tinggal di sekitar area demplot penelitian. Demplot penelitian menerapkan metode Soil Bioengineering dengan memadukan rumput vertiver penguat teras serta sulingan air. Responden yang berada di sekitar demplot belum mendapatkan sosialisasi secara terstruktur dan menyeluruh, hanya pengenalan dan sedikit pengantar penjelasan tentang teknologi yang ditawarkan. Data sekunder diambil melalui dokumentasi dan studi literatur terhadap buku-buku, laporan maupun artikel ilmiah.

2. Teknik Analisis Data

Analisis data dilakukan dengan kombinasi analisis kuantitatif dan kualitatif. Pendekatan kuantitatif dipadukan dengan pendekatan kualitatif dengan dukungan kuantifikasi data kualitatif (Herawati, Widjayanto, Saharuddin, \& Eriyatno, 2010). Data yang digunakan adalah data primer yang diambil dengan menggunakan kuesioner. Data primer meliputi karakteristik responden dan persepsi petani terhadap inovasi teknologi Soil Bioengineering berupa variabel-variabel penilaian yang terdiri dari indikator (Tabel 1a) yang kemudian diukur dengan menggunakan skala Likert (Tabel 1b) . 
Tabel (Table) 1a. Variabel dan indikator penilaian persepsi petani (Variables and indicators assessment of farmer percepsion)

\begin{tabular}{|c|c|c|}
\hline No. & $\begin{array}{l}\text { Variabel Penilaian } \\
\text { (Assesment variables) }\end{array}$ & $\begin{array}{l}\text { Indikator-indikator } \\
\text { (Indicators) }\end{array}$ \\
\hline 1. & $\begin{array}{l}\text { Keuntungan relatif } \\
\text { (Relative advantage) }\end{array}$ & $\begin{array}{l}\text { Kemudahan memperoleh alat dan bahan } \\
\text { Mahal dan murahnya biaya yang dikeluarkan } \\
\text { Aman tidaknya untuk masyarakat dan lingkungan } \\
\text { Kerugian yang ditimbulkan dari adopsi inovasi teknologi tersebut }\end{array}$ \\
\hline 2. & $\begin{array}{l}\text { Kesesuaian } \\
\text { (Compatibility) }\end{array}$ & $\begin{array}{l}\text { Sesuai dan tidak bertentangan keyakinan/ agama } \\
\text { Sesuai dan tidak bertentangan dengan budaya } \\
\text { Sesuai dengan kebutuhan masyarakat } \\
\text { Sesuai dengan kondisi lingkungan }\end{array}$ \\
\hline 3. & $\begin{array}{l}\text { Keserhanaan } \\
\text { (Simplicity) }\end{array}$ & $\begin{array}{l}\text { Pemahaman terhadap konservasi tanah dan air } \\
\text { Pemahaman terhadap pembuatan teknik Soil Bioengineering } \\
\text { Perkiraan kemampuan responden membuat teknik Soil Bioengineering }\end{array}$ \\
\hline 4. & $\begin{array}{l}\text { Ketercobaan } \\
\text { (Trialability) }\end{array}$ & $\begin{array}{l}\text { Pengetahuan responden tentang demplot yang sedang dan telah dibuat oleh tim } \\
\text { peneliti } \\
\text { Pengetahuan tentang manfaat demplot tersebut }\end{array}$ \\
\hline 5. & $\begin{array}{l}\text { Keteramatan } \\
\text { (Observability) }\end{array}$ & $\begin{array}{l}\text { Pengetahuan dan pemahaman responden terhadap keunggulan inovasi teknik Soil } \\
\text { Bioengineering } \\
\text { Pengetahuan dan pemahaman responden terhadap kekurangan inovasi teknik Soil } \\
\text { Bioengineering }\end{array}$ \\
\hline
\end{tabular}

Sumber (Source): Aditiawati et al., 2014 yang sudah dimodifikasi

Tabel (Table) 1b. Skor Skala Likert (Likert Scale Score)

\begin{tabular}{cc}
\hline Skor (Score) & Uraian (Description) \\
\hline 1 & Sangat tidak setuju \\
2 & Tidak setuju \\
3 & Ragu-ragu \\
4 & Setuju \\
5 & Sangat setuju \\
\hline
\end{tabular}

Sumber (Source): Aditiawati et al., 2014

Data hasil analisis tersebut, kemudian dianalisis lebih lanjut dengan formula:

Skor maksimal $($ Smax $)=$ skor terbesar $x$ Lindikator

Skor minimum $(\operatorname{Smin})=$ skor terkecil $x$ Eindikator

$\operatorname{Median}(M e)=\frac{S \max +S \min }{2}$

Nilai kuartil ke $1(K 1)=\frac{S \min +M e}{2}$

Nilai kuartil ke $3(K 3)=\frac{5 \max +M e}{2}$

Berdasarkan hasil analisis dengan formula di atas, maka persepsi petani terhadap inovasi teknologi konservasi tanah dan air dapat dikategorikan berdasarkan ketentuan (Aditiawati et al., 2014) pada Tabel 2 berikut.
Tabel (Table) 2. Kategori Persepsi (Perseption Category)

\begin{tabular}{cc}
\hline Skor (Score) & Kategori (Category) \\
\hline $\mathrm{K} 3 \leq \mathrm{X} \leq$ skor max & Sangat positif \\
$\mathrm{Me} \leq \mathrm{X}<\mathrm{K} 3$ & Positif \\
$\mathrm{K} 1 \leq \mathrm{X}<\mathrm{Me}$ & Negatif \\
Skor $\min \leq \mathrm{X}<\mathrm{K} 1$ & Sangat negatif \\
\hline Sumber (Source): Aditiawati et al., 2014
\end{tabular}

\section{HASIL DAN PEMBAHASAN}

\section{A. Aplikasi Teknik Soil Bioengineering}

Teknik Soil Bioengineering digunakan untuk meningkatkan kestabilan lereng. Trung (2009) dan Lestari (2017) menyampaikan bahwa pada teknik ini, vegetasi sebagai komponen utama harus melalui upaya pemilihan karena tidak semua jenis vegetasi dapat diterapkan untuk stabilisasi lereng. Agar mendapatkan jenis vegetasi yang tepat, maka jenis vegetasi yang sesuai dengan rentang elevasi juga harus menjadi pertimbangan (Riyanto, 2016). Selain elevasi, vegetasi yang dapat digunakan adalah 
vegetasi yang memiliki perakaran yang dalam dan rapat. Hal ini seperti disampaikan oleh Darmawan, Sholichin, Limantara, \& Andawayanti (2014) bahwa tanaman dengan perakaran yang dalam mampu mencegah longsor dangkal. Vegetasi penutup tanah seperti rumput yang tebal atau hutan yang lebat dapat mengurangi pengaruh topografi yang sering menyebabkan erosi dan longsor (Adhitya, Rusdiana, \& Saleh, 2016).

Berdasarkan hal tersebut, maka teknik Soil Bioengineering yang digunakan dalam penelitian ini adalah pemanfaatan rumput vertiver sebagai komponen vegetasi utama. Menurut Sittadewi (2017) vertiver mempunyai sistem penetrasi akar yang dalam, kemampuan mengikat tanah yang baik serta mampu hidup pada berbagai jenis tanah (Sittadewi, 2017). Keunggulan lain dari vertiver adalah pertumbuhan yang cepat serta dapat membentuk pagar yang rapat apabila ditanam dengan pola tertentu (Noor, Vahlevi, \& Fathurrozi, 2011). Selain vertiver pada penelitian ini digunakan pula pagar bambu serta penambahan sulingan air. Pemasangan pagar bambu dan sulingan air dilakukan untuk memperkuat lereng serta mengurangi kejenuhan air, sehingga lereng menjadi lebih aman, dan potensi longsor dapat berkurang.

\section{B. Karakteristik Responden}

Perkembangan individu termasuk persepsinya terhadap sesuatu ditentukan faktor lingkungan. Faktor lingkungan yang berperan penting dalam perkembangan individu yaitu lingkungan sosial dan lingkungan ekonomi. Keberagaman persepsi juga ditentukan oleh faktor personal yang ada pada diri individu, yaitu: umur, pendidikan, pengetahuan, pengalaman, luas penguasaan lahan dan sebagainya (Pratama, 2010). Responden dalam penelitian ini mempunyai karakteristik tertentu yang mewakili persepsinya terhadap teknik Soil Bioengineering untuk mengatasi longsor. Karakteristik petani calon pengguna teknik Soil Bioengineering yang dikaji dalam penelitian ini berdasarkan pada golongan umur, pendidikan terakhir, luas lahan garapan, komoditi yang ditanam, pengalaman bertani dan tingkat pendapatan (Tabel 3).

\section{Berusia produktif}

Umur responden akan menentukan kematangan dalam berpikir terutama dalam mengemukakan persepsi maupun kemauan dalam mengadopsi teknik Soil Bioengineering yang diterapkan oleh BP2TPDAS. Sebagian besar responden (40\%) merupakan petani dengan usia produktif 41-55 tahun. Petani golongan usia produktif diharapkan dapat menjadi pelopor (pioneer) dalam adopsi karena kemampuan kerjanya masih optimal dalam usaha tani. Golongan umur produktif berpeluang dalam upaya peningkatan produktivitas usaha mereka karena umur produktif sangat berpengaruh dengan kemampuan fisik petani untuk bekerja secara optimal (Aditiawati et al., 2014). Sebagian besar warga Sijeruk memutuskan menjadi petani setelah menjelang usia 30 tahun, karena pada usia muda (dibawah 30 tahun) mereka bekerja di luar daerah atau di perkotaan untuk mencari pengalaman kerja. 
Tabel (Table) 3. Karakteristik responden (Respondents characteristics)

\begin{tabular}{|c|c|c|c|}
\hline $\begin{array}{l}\text { No. } \\
\text { (No). }\end{array}$ & Karakteristik responden (Respondents characteristics) & $\begin{array}{l}\text { Jumlah orang } \\
\text { (Total people) }\end{array}$ & $\begin{array}{c}\text { Persentase (Percentage) } \\
(\%)\end{array}$ \\
\hline \multirow[t]{6}{*}{1.} & Usia (Age) & & \\
\hline & $21-30$ & 5 & 14,29 \\
\hline & $31-40$ & 9 & 25,71 \\
\hline & $41-50$ & 14 & 40,00 \\
\hline & $51-60$ & 6 & 17,14 \\
\hline & $61<$ & 1 & 2,86 \\
\hline \multirow[t]{6}{*}{2.} & Pendidikan Terakhir (The Last education) & & \\
\hline & Tidak Sekolah (No school) & - & - \\
\hline & SD (Elementary school) & 5 & 14,29 \\
\hline & SMP (Yunior high school) & 29 & 82,85 \\
\hline & SMA (Senior high school) & 1 & 2,86 \\
\hline & Sarjana (Bachelor) & - & - \\
\hline \multirow[t]{7}{*}{3.} & $\begin{array}{l}\text { Luas lahan garapan (The area of arable land) (hektar/ } \\
\text { hectar) }\end{array}$ & - & - \\
\hline & $<0,1$ & 23 & 65,71 \\
\hline & $0,1-0,29$ & 7 & 20,00 \\
\hline & $0,3-0,49$ & 3 & 8,57 \\
\hline & $0,5-0,69$ & 1 & 2,86 \\
\hline & $0,7-0,89$ & 1 & 2,86 \\
\hline & $0,9<$ & & \\
\hline \multirow[t]{6}{*}{4.} & Komoditi yang ditanam (Planted commodity) & & \\
\hline & Salak & 19 & 54,28 \\
\hline & Salak, sengon & 7 & 20,00 \\
\hline & Salak, ubi kayu & 5 & 14,29 \\
\hline & Salak, jagung & 3 & 8,57 \\
\hline & Salak, padi & 1 & 2,86 \\
\hline \multirow[t]{8}{*}{5.} & Pengalaman bertani (Farming experience) (tahun/ year) & & \\
\hline & $<5$ & 1 & 2,86 \\
\hline & $5-10$ & 2 & 5,71 \\
\hline & $11-15$ & 7 & 20,00 \\
\hline & $16-20$ & 15 & 42,86 \\
\hline & $21-25$ & 6 & 17,14 \\
\hline & $26-30$ & 3 & 8,57 \\
\hline & $30<$ & 1 & 2,86 \\
\hline \multirow[t]{8}{*}{6.} & Tingkat pendapatan (Income level) (rupiah) & & \\
\hline & $<1$ & 2 & 5,71 \\
\hline & $1-2,99$ & 14 & 40,00 \\
\hline & $3-4,99$ & 17 & 48,57 \\
\hline & $5-6,99$ & 1 & 2,86 \\
\hline & $7-8,99$ & - & - \\
\hline & $9-10,99$ & - & - \\
\hline & $11<$ & 1 & 2,86 \\
\hline
\end{tabular}

Sumber (Source): Analisis data (Data analysis), 2019

2. Tingkat pendidikan rendah

Sebagian besar responden berpendidikan SD $(14,3 \%)$ dan SMP $(82,9 \%)$, oleh sebab itu memilih pekerjaan sebagai petani karena untuk menjadi petani tidak memerlukan pendidikan formal yang tinggi. Pendidikan formal sangat berpengaruh terhadap keputusan responden dalam menerima inovasi baru, semakin tinggi pendidikan responden maka akan lebih luas pengetahuan 
responden dan dapat lebih mudah menerima inovasi baru (Siswadi \& Syakir, 2016). Makin tinggi tingkat pendidikan formal petani diharapkan makin rasional dalam pola pikir dan juga daya nalarnya pendidikan yang semakin tinggi diharapkan dapat lebih mudah merubah sikap dan perilaku untuk bertindak lebih rasional. Sumberdaya manusia (SDM) petani masih tergolong rendah, sebab tingkat pendidikan seseorang menentukan keberhasilan dalam mengelola usahataninya. Rendahnya tingkat pendidikan akan berpeluang besar terhadap kegagalan penerimaan adopsi teknik Soil Bioengineering karena keterbatasan pemahaman dan kapasitas sumber daya manusia.

\section{Luas lahan garapan yang terbatas (sempit)}

Luas garapan merupakan keseluruhan luas lahan yang diusahakan petani responden baik milik sendiri, menyewa, maupun gadai. Luas lahan garapan akan berpengaruh terhadap persepsi dan adopsi inovasi. Luas lahan yang sempit akan menjadikan persepsi yang negatif dan tingkat adopsi yang rendah. Hal ini karena luas lahan mempengaruhi besarnya pendapatan yang diterima oleh petani walaupun besarnya pendapatan juga tergantung pada jumlah dan jenis tanaman pertanian yang diusahakan (Yulida, 2012). Semakin luas penguasaan lahan yang digunakan untuk kegiatan usahatani maka akan semakin tinggi pula hasil produksinya (Aditiawati et al., 2014). Sebagian besar responden $(65,7 \%)$ mengusahakan lahan antara 0,1 sampai 0,29 ha relatif sempit untuk lahan pertanian. Keterbatasan lahan menjadikan ancaman terhadap penerimaan adopsi teknik Soil Bioengineering, karena dianggap mengurangi space tanaman dan tidak menguntungkan petani. Kecamatan Banjarmangu mempunyai kepadatan penduduk yang relatif tinggi yaitu 909 penduduk $/ \mathrm{km}^{2}$ (Statistik, 2017).

4. Komoditas yang ditanam adalah buah salak (Salacca zalacca)

Komoditi yang ditanam responden akan berpengaruh terhadap persepsi dan tingkat adopsi, karena pengadopsian teknik Soil Bioengineering tersebut akan mengurangi ruang tanam komoditi yang ditanam. Sehingga ada kemungkinan persepsi petani dalam hal ini negatif dan tingkat adopsinya terhadap inovasi teknik Soil Bioengineering rendah. Sebagian besar responden (54,3\%) menanam salak saja dan sebagian lainnya menanam salak dicampur dengan tanaman sengon (Paraserianthes falcaria) dan singkong (Manihot esculanta).

Kecamatan Banjarmangu merupakan sentra produksi salak. Tanaman salak masih mempunyai daya tarik yang tinggi untuk ditanam karena panennya dapat dilakukan hampir sepanjang tahun. Demikian halnya dengan singkong dan sengon, keduanya juga merupakan komoditas utama Kabupaten Banjarnegara (Statistik, 2017). Adopsi teknik Soil Bioengineering yang diterapkan pada demplot penelitian diharapkan dapat diterapkan oleh petani yang sebagian besar menanam salak dengan menyisipkan tanaman-tanaman penahan longsor yang disarankan dalam teknik Soil Bioengineering.

\section{Pengalaman sebagai petani}

Sebagian besar responden (42,9\%) berpengalaman 16-20 tahun dalam bertani, untuk meneruskan pekerjaan orang tuanya dan dilakukan sejak kecil untuk membantu orang tuanya bertani. Pengalaman petani dalam berusaha berpengaruh terhadap cara merespon suatu inovasi. Semakin lama pengalaman berusaha, maka tingkat respon 
positif terhadap suatu teknologi semakin tinggi. Demikian juga halnya dengan persepsi dan tingkat adopsinya. Diharapkan petani dengan pengalaman yang lama, persepsinya positif dan kemauan adopsi teknik Soil Bioengineering akan tinggi. Pengalaman berusaha sangat penting dalam rangka pengelolaan usahatani (Aditiawati et al., 2014; Manyamsari \& Mujiburrahmad, 2014). Pengalaman yang lama dalam bertani diharapkan dapat meningkatkan respon petani terhadap adopsi teknik Soil Bioengineering.

6. Tingkat pendapatan total rumah tangga yang sedang

Pendapatan total rumah tangga merupakan pendapatan yang diperoleh responden baik dari kegiatan usahatani maupun luar usahatani. Petani dengan pendapatan yang tinggi akan cenderung lebih cepat untuk menerima dan menerapkan suatu inovasi karena seseorang dengan pendapatan tinggi cenderung lebih berani mencoba hal-hal baru yang ada di sekitar mereka (Aditiawati et al., 2014). Sebagian besar responden (48,6\%) berpenghasilan antara 3 sampai 4,9 juta rupiah per bulan yang tergolong berpenghasilan sedang atau menengah. Sisanya berpenghasilan tinggi dan rendah. Sebenarnya penghasilan responden yang tinggi dan sedang diharapkan dapat mendukung peningkatan adopsi teknik Soil Bioengineering. Namun responden berharap biaya yang dikeluarkan untuk penerapan teknologi konservasi tanah dan air tersebut tidak mengurangi pendapatannya, karena masih banyak kebutuhan-kebutuhan lain yang harus dibiayai oleh responden. Responden berharap adanya bantuan dan fasilitasi dari pemerintah atau instansi terkait untuk membantu masyarakat dalam penerapan teknik Soil Bioengineering.

\section{Persepsi Masyarakat Terhadap Teknik Soil Bioengineering}

Tingkat adopsi dari suatu inovasi tergantung pada persepsi masyarakat yang dijadikan sasaran pengguna teknik Soil Bioengineering terkait dengan karakteristik inovasi teknologi tersebut. Ada lima karakteristik yang mendukung penjelasan tingkat adopsi dari suatu inovasi yaitu: 1) Keuntungan-keuntungan relatif (relative advantages); yaitu sejauh mana suatu inovasi dianggap lebih baik daripada inovasi sebelumnya. Keuntungan relatif ini meliputi tingkat profitabilitas ekonomi, biaya yang rendah, rasa nyaman, penghematan waktu dan usaha serta insentif. 2) Kesesuaian (compactibility); yaitu apakah inovasi mempunyai sifat lebih sesuai dengan nilai yang ada, pengalaman sebelumnya, dan kebutuhan yang diperlukan penerima/ adopter. 3) Kesederhanaan (simplicity); yakni apakah inovasi tersebut dirasakan sederhana (simpel) atau rumit untuk dipahami dan digunakan. 4) Dapat dicobakan (trialability); yaitu suatu inovasi akan mudah diterima apabila dapat dicobakan dalam ukuran kecil. 5) Dapat dilihat (observability); yaitu suatu inovasi dapat disaksikan dengan mata. Semakin mudah bagi individu untuk melihat hasil sebuah inovasi, semakin besar kemungkinan mereka untuk mengadopsi (Aditiawati et al., 2014).

Pengukuran persepsi petani terhadap teknik Soil Bioengineering dapat dilihat berdasarkan penilaian-penilaian karakteristik inovasi yang ditawarkan (Tabel 4). 
Tabel (Table) 4. Persepsi responden berdasarkan penilaian pada karakteristik inovasi (Perceptions of respondents based on an assessment of the characteristics of innovation

\begin{tabular}{llcccc}
\hline $\begin{array}{c}\text { No } \\
\text { (No) }\end{array}$ & $\begin{array}{c}\text { Persepsi Responden berdasar } \\
\text { penilaian (Perceptions of } \\
\text { respondents based on an } \\
\text { assessment) }\end{array}$ & $\begin{array}{c}\text { Kategori Persepsi } \\
\text { (Percepsion } \\
\text { category) }\end{array}$ & $\begin{array}{c}\text { Kategori } \\
\text { Skor } \\
\text { (Score } \\
\text { category) }\end{array}$ & $\begin{array}{c}\text { Jumlah } \\
\text { responden } \\
\text { (Number of } \\
\text { respondents) }\end{array}$ & $\begin{array}{c}\text { Persentase } \\
\text { (Percentage) }\end{array}$ \\
\hline 1. & Keuntungan relatif & & 7 & 20,00 \\
& (Relative advantage) & Sangat positif & $8-10$ & 54,28 \\
& & Positif & $6-8$ & 19 & 11,43 \\
& & Negatif & $4-6$ & 4 & 14,29 \\
\hline 2. & Kesesuaian & Sangat negatif & $2-4$ & 5 & 25,72 \\
& (Compatibility) & Sangat positif & $8-10$ & 9 & 60,00 \\
& & Positif & $6-8$ & 21 & 5,71 \\
& & Negatif & $4-6$ & 2 & 8,57 \\
\hline 3. & Kesederhanaan (Simplicity) & Sangat negatif & $2-4$ & 3 & 22,86 \\
& & Sangat positif & $8-10$ & 8 & 51,42 \\
& & Positif & $6-8$ & 18 & 11,43 \\
& & Negatif & $4-6$ & 4 & 14,29 \\
\hline 4. & Dapat dicobakan/ketercobaan & Sangat negatif & $2-4$ & 5 & 5,71 \\
& (Trialability) & Sangat positif & $8-10$ & 2 & 91,43
\end{tabular}

Sumber (Source): Analisis data (Data analysis), 2019

\section{Keuntungan relatif (Relative advantage)}

Salah satu pertimbangan petani untuk mengadopsi suatu inovasi adalah apabila inovasi tersebut menguntungkan bagi calon adopternya. Persepsi petani terhadap keuntungan relatif teknik Soil Bioengineering dapat dilihat dari dua indikator yaitu biaya pembuatannya murah dan aman untuk lingkungan. Indikator-indikator dalam karakteristik inovasi ini adalah: kemudahan memperoleh alat dan bahan, mahal dan murahnya biaya yang dikeluarkan, aman tidaknya untuk masyarakat dan lingkungan dan kerugian yang ditimbulkan dari adopsi inovasi teknologi tersebut.

Persepsi responden terhadap keuntungan teknik Soil Bioenginering, sebagian besar positif (54,3\%). Responden menganggap teknik Soil Bioengineering yang ditawarkan murah dan aman untuk lingkungan berdasarkan pengamatan mereka pada demplot uji coba. Oleh sebab itu, responden menganggap teknologi tersebut bisa diterapkan untuk mencegah tanah longsor. Penggunaan rumput vetiver dan sulingan air yang berasal dari bambu merupakan kombinasi Soil Bioengineering yang dapat diterapkan sebagai upaya teknik konservasi tanah dan air. Teknik konservasi Soil Bioengineering dapat menggunakan bahan baku lokal yang murah dan mudah untuk dilakukan oleh masyarakat. Bahan-bahan tersebut murah dan mudah didapatkan. Demikian juga dengan pemilihan jenis-jenis 
tanaman yang berakar serabut dan panjang yang direkomendasikan.

\section{Kesesuaian (Compatibility)}

Persepsi petani terhadap kesesuaian teknik Soil Bioengineering dilihat dari kesesuaian inovasi tersebut dengan kondisi dan kebiasaan masyarakat, kebutuhan, dan kondisi lingkungan. Indikator-indikatornya adalah kesesuaian teknologi tersebut dengan keyakinan, kebudayaan dan kebutuhan masyarakat.

Sebagian besar responden (60\%) mempunyai persepsi yang positif terhadap kesesuaian teknik Soil Bioengineering sebagai teknik untuk mitigasi longsor di lahan pertaniannya. Teknik ini dipandang sesuai dan tidak bertentangan keyakinan, kebudayaan dan kebutuhan masyarakat dan kondisi lingkungan, karena teknik ini mudah dilakukan dan diadaptasikan sesuai dengan kondisi masyarakat dan lingkungan serta sesuai dengan kebutuhan masyarakat dalam mitigasi longsor di lahan pertaniannya. Walaupun sebenarnya teknik ini dapat dilakukan secara mandiri, responden berharap ada bantuan dari pemerintah terutama dalam pembiayaan dan pendampingan.

\section{Kesederhanaan (Simplicity)}

Kesederhanaan atau simpelnya suatu inovasi dapat mempengaruhi cepat tidaknya seseorang mengadopsi inovasinya. Kesederhanaan teknik Soil Bioenginering dapat diukur melalui persepsi responden terhadap inovasi tersebut yang meliputi sulit tidaknya pemahaman responden dalam membuat dan mengaplikasikan teknik tersebut. Indikator-indikatornya adalah: pemahaman terhadap konservasi tanah dan air, pemahaman terhadap pembuatan teknik tersebut dan perkiraan kemampuan responden membuat teknik tersebut.

Sebagian besar responden menilai positif $(51,4 \%)$ terhadap kesederhanaan teknik Soil Bioengineering, dengan kata lain pemahaman responden terhadap aplikasi teknik tersebut sederhana dan tidak rumit (mudah). Penerapan teknik tersebut mudah karena bahan-bahan yang diperlukan maupun tanaman yang ditanam mudah didapatkan oleh responden, selain itu teknik tersebut tidak rumit dalam pembuatnya, sehingga mudah dipahami dan diujicobakan di lahan pertanian warga. Para responden menyatakan bersedia menerapkan teknik tersebut sepanjang pemerintah mau memfasilitasi baik dalam hal pendanaan maupun pendampingan.

\section{Ketercobaan/ dapat dicobakan (Trialability)} Sebelum suatu inovasi dapat diadopsi oleh pengguna, maka inovasi tersebut harus sudah diujicobakan secara terbatas pada skala yang kecil. Teknik Soil Bioengineering ini sudah dujicobakan pada demplot-demplot dibuat oleh tim peneliti BP2TPDAS dan para responden sudah melihat dan mengamati pembuatannya. Namun responden belum mengujicobakan secara sendiri dalam penelitian ini. Indikator-indikatornya adalah: pengetahuan responden tentang demplot yang sedang dan telah dibuat oleh tim peneliti dan pengetahuan tentang manfaat demplot tersebut.

Sebagian besar responden $(91,4 \%)$ menilai positif terhadap teknik Soil Bioengineering berdasarkan demplot uji coba BP2TPDAS. Oleh sebab itu, responden dapat mempertimbangkan adopsi teknologi tersebut 
di lahan pertaniannya untuk mitigasi terhadap longsor.

5. Keteramatan /dapat dilihat (Observability)

Keteramatan teknik Soil Bioengineering artinya inovasi ini dapat diamati petani sebagai calon pengguna. Hal ini dapat mempengaruhi persepsi petani terhadap keunggulan dan kelemahan dari teknik tersebut. Indikator-indikatornya adalah pengetahuan dan pemahaman responden terhadap keunggulan dan kekurangan inovasi teknik Soil Bioengineering.

Sebagian besar responden menilai positif $(88,6 \%)$ terhadap keteramatan teknik Soil Bioengineering. Berdasarkan wawancara dengan responden dalam pengamatannya, teknik ini ramah lingkungan dan tidak mengganggu produktivitas lahan serta vegetasi-vegetasi yang direkomendasikan oleh peneliti. Disamping itu penggunaan teknik ini diharapkan mendatangkan penghasilan yang baik untuk petani. Terutama dalam hal peningkatan produktivitas buah dan kayu. Mengingat sebagian besar responden menanam komoditas salak yang dicampur dengan tanaman sengon.

\section{IV.KESIMPULAN}

Karakteristik petani calon pengguna teknik Soil Bioengineering adalah: 1) berusia produktif (41-55 tahun), 2) berpendidikan rendah $(\mathrm{SMP}), 3)$ luas lahan yang sempit $(0,1$ sampai 0,3 hektar), 4) komoditi yang ditanam adalah salak, 5) Berpengalaman sebagai bertani (16 - 20 tahun) dan, 6) tingkat pendapatan yang sedang/ menengah (1-2,9 juta rupiah per bulan). Persepsi petani umumnya positif terhadap teknik Soil Bioengineering yang diukur berdasarkan: 1) keuntungan relatif, 2) kesesuaian, 3) kesederhanaan, 4) ketercobaan dan 5) keteramatan. Walaupun sebagian besar responden berpendapatan sedang atau menengah dan mampu untuk menerapkan teknik Soil Bioengineering, namun mereka berharap mendapatkan bantuan (insentif) dan bimbingan dalam pembuatannya. Selanjutnya perlu dilakukan penelitian pengaruh karaktersistik responden terhadap persepsi dan tingkat adopsi teknik Soil Bioengineering serta analisis lanjutan terhadap efektifitas teknologi tersebut dan pengaruhnya terhadap produktifitas lahan pertanian.

\section{UCAPAN TERIMA KASIH}

Ucapan terimakasih disampaikan kepada Kepala BPPTPDAS Solo beserta staf sehingga kegiatan penelitian ini dapat berjalan. Terimakasih disampaikan pula kepada seluruh tim penelitian ini, baik peneliti maupun teknisi selama penelitian berlangsung.

\section{DAFTAR PUSTAKA}

Adhitya, F., Rusdiana, O., \& Saleh, M. B. (2016). Penentuan jenis tumbuhan lokal dalam upaya mitigasi longsor dan teknik budidayanya pada areal rawan longsor di KPH Lawu DS: Studi kasus di RPH Cepoko. Jurnal Silvikultur Tropika, 8(1), 9-19. Retrieved from https://jurnal.ipb.ac.id/index.php/jsilvik/ article/download/16869/12267

Aditiawati, P., Rosmiati, M., \& Sumardi, D. (2014). Persepsi petani terhadap inovasi teknologi pestisida nabati limbah tembakau (Suatu kasus pada petani tembakau di Kabupaten Sumedang). Sosiohumaniora, 16(2), 184-192. https://doi.org/10.24198/sosiohumanior a.v16i2.5731 
Darmawan, A. R., Sholichin, M., Limantara, L. M., \& Andawayanti, U. (2014). Studi potensi tanah longsor dan upaya pengendaliannya di Wilayah Sub DAS Konto Hulu. Jurnal Teknik Pengairan, 5(1), 68-78. Retrieved from http://jurnalpengairan.ub.ac.id/index.ph p/jtp/article/download/206/200

Herawati, T., Widjayanto, N., Saharuddin, \& Eriyatno. (2010). Analisis respon pemangku kepentingan di daerah terhadap kebijakan hutan tanaman rakyat. Analisis Kebijakan Kehutanan, 7(1), $13-25$. https://doi.org/10.20886/jakk.2010.7.1.1 3-25

Idjudin, A. A. (2011). Peranan konservasi lahan dalam pengelolaan perkebunan. Jurnal Sumberdaya Lahan , 5(2), 103-1116. Retrieved from https://media.neliti.com/media/publicati ons/133004-ID-none.pdf

Irayani, Z., Permanajati, I., Haryadi, A., Wihantoro, \& Azis, A. N. (2016). Investigasi bidang gelincir tanah longsor dengan metode tahanan jenis dan pengujian sifat plastisitas tanah (Studi kasus di Bukit Pawinihan, Sijeruk, Banjarmangu, Banjarnegara). Dinamika Rekayasa, 12(2), 53-57.

https://doi.org/10.20884/1.dr.2016.12.2. 145

Lestari, Endah (2017) Sistem drainase untuk aliran bawah tanah rawan longsor (Studi kasus di Sub DAS Cikapundung Bandung). Jurnal Forum Mekanika, 6(1),1-7.

Manyamsari, I., \& Mujiburrahmad. (2014). Karakteristik petani dan hubungannya dengan kompetensi petani lahan sempit (Kasus: Di Desa Sinar Sari Kecamatan
Dramaga Kabupaten Bogor Jawa Barat). Agrisep, 15(2), 58-75. Retrieved from http://www.jurnal.unsyiah.ac.id/agrisep/ article/viewFile/2099/2050

Noor, A., Vahlevi, J., \& Fathurrozi. (2011). Stabilisasi lereng untuk pengendalian erosi dengan soil bioengineering menggunakan akar rumput vetiver. Jurnal Poros Teknik, 3(2), 69-74. Retrieved from https://media.neliti.com/media/publicati ons/126453-ID-stabilisasi-lereng-untukpengendalian-er.pdf

Nugroho, P., Soedjoko, S. A., Kusumandari, A., \& Marhaento, H. (2013). Adaptasi dan mitigasi bencana tanah longsor melalui penguatan kapasitas masyarakat dan peningkatan produktivitas lahan melalui sistem agroforestri. In D. P. Kuswantoro, T. S. Widyaningsih, E. Fauziyah, \& R. Rachmawat (Eds.), Proseding Seminar Agroforestri. Malang: Kerjasama Balai Penelitian Teknologi Agroforestry, Fakultas Pertanian Universitas Brawijaya, World Agroforestry Centre (ICRAF), dan Masyarakat Agroforestri Indonesia. Retrieved from https://www.researchgate.net/publicatio n/272823309_Adaptasi_dan_mitigasi_be ncana_tanah_longsor_melalui_penguata n_kapasitas_masyarakat_dan_peningkat an_produktivitas_lahan_melalui_sistem_ agroforestri?enrichld=rgreqf6cf023ea192f3572f2a1fe4c6d46883XXX\&enric

Pratama, K. B. (2010). Hubungan karakteristik petani dengan persepsi petani terhadap sistem resi gudang komoditas padi di Kecamatan Jaten, Kabupaten Karanganyar. Universitas Negeri Sebelas Maret. Retrieved from https://eprints.uns.ac.id/4596/1/138611 008201007261.pdf 
Riyanto, Heru D. (2016) Rekayasa vegetasi untuk mengurangi longsor. Surakarta. Balai Penelitian dan Pengembangan Teknologi Daerah Aliran Sungai.

Sari, D. P. (2016). Manajemen resiko dan mitigasi bencana longsor di kawasan Model DAS Mikro Watugede Gunung Kidul. Universitas Gadjah Mada.

Setiawan, H. (2014). Analisis tingkat kapasitas dan strategi coping masyarakat lokal dalam menghadapi bencana longsor, studi kasus di Tawangamangu, Karanganyar, Jawa Tengah. Jurnal Penelitian Sosial Dan Ekonomi Kehutanan, 11(1), 70-81.

Siswadi, B., \& Syakir, F. (2016). Respon petani terhadap program pemerintah mengenai Asuransi Usaha Tani Terpadu (AUTP). In Proseding Seminar Nasional Pembangunan Pertanian (pp. 169-177). Malang: Fakultas Pertanian Universitas Brawijaya. Retrieved from https://fp.ub.ac.id/semnas/Paper/29_as uransi_padi-bambang_siswadi_(169177).pdf

Sittadewi, E. H. (2017). Peran vegetasi dalam aplikasi soil bioengineering. Jurnal Sains Dan Teknologi Mitigasi Bencana, 12(2), 29-36. Retrieved from http://ejurnal.bppt.go.id/index.php/JST $\mathrm{MB} /$ article/view/2588

Statistik, B. P. (2017). Banjarnegara dalam angka tahun 2017. Banjarnegara.
Susanti, P. D., Miardini, A., \& Harjadi, B. (2017). Analisis kerentanan tanah longsor sebagai dasar mitigasi di Kabupaten Banjarnegara. Jurnal Penelitian Pengelolaan Daerah Aliran Sungai, 1(1), 49-59.

https://doi.org/10.20886/jppdas.v1i1.25 02.g2073

Tejakusuma, I.G. (2016). Soil Bioengineering dan peranannya dalam geologi lingkungan. Jurnal Sains dan Teknologi Mitigasi Bencana, 11 (1), 51-57.

Trung, Nguyen M. (2009) Development of slope protection system for landslide prevention by bioengineering in Kalibawang, Indonesia. Universitas Gadjah Mada

Yulida, R. (2012). Kontribusi usaha tani pekarangan terhadap ekonomi rumah tangga petani di Kecamatan Kerinci Kabupaten Pelalawang. Indonesian Journal of Agricultural Economics (IJAE), 3(2), 135-154. Retrieved from https://ejournal.unri.ac.id/index.php/IJA E/article/view/1549/1524

Zakaria, Z., Muslim, D., Sophian, R. I., Kuswaryan, S., \& Tanuwirya, U. H. (2013). Bio-engineering, melalui pemanfaatan tanaman kaliandra (Caliandra calothyrsus) di wilayah zona rawan longsor, Jawa Barat. Bulletin of Scientific Contribution, 11(3), 168-175. 